\title{
Intersection of chronic pain treatment and opioid analgesic misuse: causes, treatments, and policy strategies
}

This article was published in the following Dove Press journal:

Substance Abuse and Rehabilitation

17 August 2011

Number of times this article has been viewed

\author{
Amy Wachholtz' \\ Gerardo Gonzalez' \\ Edward Boyer ${ }^{2}$ \\ Zafar N Naqvi' \\ Christopher Rosenbaum² \\ Douglas Ziedonis' \\ 'Department of Psychiatry, \\ ${ }^{2}$ Department of Emergency Medicine, \\ University of Massachusetts Medical \\ School, Worcester, MA, USA
}

\begin{abstract}
Treating chronic pain in the context of opioid misuse can be very challenging. This paper explores the epidemiology and potential treatments for chronic pain and opioid misuse and identifies educational and regulation changes that may reduce diversion of opioid analgesics. We cover the epidemiology of chronic pain and aberrant opioid behaviors, psychosocial influences on pain, pharmacological treatments, psychological treatments, and social treatments, as well as educational and regulatory efforts being made to reduce the diversion of prescription opioids. There are a number of ongoing challenges in treating chronic pain and opioid misuse, and more research is needed to provide strong, integrated, and empirically validated treatments to reduce opioid misuse in the context of chronic pain.
\end{abstract}

Keywords: addiction, dependence, diversion, comorbid, narcotic, treatment

\section{Introduction}

Opioid analgesics remain the mainstay of pharmacologic treatment for acute and chronic pain. However, the risks for misuse and development of addiction have raised concerns for clinicians, public health specialists, and the community at large. The concern about prescription drug addiction has resulted in new state and federal policies and monitoring systems, and yet there is a need to help the increasing number of Americans suffering from chronic pain. The number of prescriptions for opioid analgesics has risen dramatically over the last decade, ${ }^{1}$ and at the same time, reports of misused or abused opioids have led to increasing concerns about diversion of these potent drugs. ${ }^{2,3}$

Although the administration of opioids in the management of acute pain carries little risk, long-term use of opioid analgesics is associated with clinically relevant rates of abuse or addiction. This review will focus on the relationship between noncancer pain, opioid analgesics, opioid misuse, and the diversion of these narcotics. Pharmacotherapy and psychosocial treatment strategies for prescription drug addiction and pain management are reviewed, including broader policy strategies.

\section{Epidemiology of pain and addiction}

It is estimated that up to $50 \%$ of Americans experience chronic pain or intermittent repeating pain during their lifetime. ${ }^{4}$ There is an ongoing, and often heated, discussion about how to best treat pain disorders and the role that opioid analgesics should play in the treatment of nonmalignant pain to balance the need for pain management and the risk of developing an addiction. Despite this ongoing debate, the number of
Correspondence: Amy Wachholtz

Department of Psychiatry,

School, 55 Lake Ave N

Worcester, MA 01655, USA

Tel +l 5083342164

Fax +l 5088565990

Email amy.wachholtz@umassmemorial.org 
prescriptions for opioid analgesics is on the rise. ${ }^{1}$ According to the National Ambulatory Medical Care Survey, ${ }^{5}$ pain complaints account for more than $40 \%$ of all symptoms related to outpatient visits, or over 100 million ambulatory encounters in the US alone each year. Pain costs the US over $\$ 100$ billion per year in health care and lost productivity. ${ }^{6}$ Furthermore, pain medications are the second most commonly prescribed class of drugs, accounting for $12 \%$ of all medication prescribed during ambulatory office visits in the US. ${ }^{7}$ This medical use of opioids, that increased during the 1990s in response to an effort to promote better pain control, has also been associated with a dramatic increase in the abuse of opioids that now seems to be stable. ${ }^{8}$ Since 1997, the four primary opioids used in pain treatment have increased markedly, ie, morphine (73\%), hydromorphone (96\%), fentanyl (226\%), and oxycodone (403\%). ${ }^{9}$

Concerns about diversion and addiction are also on the rise, as there are an increasing number of reported cases of misuse or abuse of opioids. ${ }^{2,3}$ However, there is significant disagreement about the frequency of opioid abuse/dependence that occurs due to prescribing for pain, with estimates ranging from a low of $3 \%$ to a high of $30 \%$ depending on the study and the methodology used. ${ }^{9,10} \mathrm{~A}$ recent large scale meta-analysis by Fishbain et al ${ }^{11}$ studied aberrant drug-related behaviors in the context of chronic opioid analgesic therapy. Aberrant behaviors may include taking medications off schedule, hoarding medications, requesting opioid analgesic refills early, taking too much or too little of the prescribed medication, or supplementing with nonprescribed drugs (legal or illicit). The results suggest that the onset of actual addiction after starting opioids for pain management is relatively low $(0.19 \%-3.2 \%)$. However, the occurrence of aberrant drug-taking behaviors is much higher (11.5\%). When analyzing only those studies that included a urinary toxicology screen, the aberrant drug-related behavior rate went even higher, with $20.4 \%$ of patients having no opioids in their urine screen, and $14.5 \%$ testing positive for other illicit drugs. ${ }^{11}$

While the likelihood of patients progressing from taking legitimately prescribed opioids for pain to opioid addiction is low, pain in the context of pre-existing opioid addiction is extremely high. A recent study of pain in the context of opioid addiction found that $80 \%$ of patients entering methadone maintenance treatment reported experiencing frequent pain. Approximately $37 \%$ of individuals entering for opioid addiction reported chronic pain compared with only $24 \%$ in a general substance abuse population. ${ }^{12}$ Among individuals entering methadone maintenance treatment for addiction who experience pain, $65 \%$ report moderate to severe pain, and pain that interferes with daily activities. ${ }^{12}$

Among individuals with comorbid opioid addiction and chronic pain, pain can significantly interfere with relapse after opioid addiction treatment. The odds of opioid relapse after detoxification in those with opioid addiction and moderate pain are 2.6 times higher than those without pain. Individuals with severe pain in the context of opioid addiction have over five times higher relapse rate compared with their nonpain counterparts with opioid addiction. ${ }^{13}$

Therefore, while conversion rates to addiction appear to be low among individuals starting opioid analgesic therapy for chronic pain, aberrant behaviors are not infrequent. Further, among those individuals with comorbid opioid addiction and pain, untreated pain can significantly hamper recovery from opioid addiction.

According to the Centers for Disease Control and Prevention, deaths from unintentional overdoses are now the second leading cause of accidental death in the US. After a steep rise beginning in the early 1990s, over 27,000 such deaths were recorded in 2007. Nearly 11,500 deaths from opioid analgesics in 2007 have contributed to this trend. Admissions to drug treatment programs increased by $400 \%$ between 1998 and 2008; opioid analgesics were the second most prevalent abused substance, after marijuana. ${ }^{14}$ Visits to emergency departments for opioid abuse more than doubled between 2004 and 2008. National prescription tracking data demonstrate that $40 \%$ of opioid prescribing is done by family practitioners, osteopaths, or internists, most frequently for musculoskeletal complaints. Approximately 3\% of the US adult population receives long-term opioid therapy for chronic noncancer pain. ${ }^{14}$

These events parallel an increase in the medical use of opioids since 1990. Two events conspired to produce this surge in opioid prescribing. First, aggressive, and ultimately illegal, marketing of OxyContin ${ }^{\circledR}$ began in 1995 following approval of the drug. Second, physicians have been encouraged to identify and ultimately treat acute and chronic pain. Sales of methadone and oxycodone quadrupled between 1997 and 2002. ${ }^{14}$ Interestingly, the number of opioid prescriptions correlated strongly with mortality, in that, states with the highest opioid prescribing rates had the highest rates for accidental opioid death. In general, per capita sales are most strongly associated with oxycodone-related and methadone-related mortality. In almost every sample, men have higher death rates than women, most commonly those aged $45-54$ years. Caucasians and Native Americans have higher death rates following overdose than African Americans. ${ }^{14}$ 


\section{Psychosocial influences of pain}

Pain is a multidimensional construct that is influenced by biological, psychological, and social factors. ${ }^{15}$ Multiple researchers have identified that the perception of pain does not correlate well with physical injury, ${ }^{16}$ and that nonphysical forms of pain can activate the same areas of the brain as physically induced pain. ${ }^{17}$ Further, research has indicated that descending pathways from the brain can be used to modulate (up or down) the messages of the ascending neural pathways. ${ }^{15}$ This suggests that the patient is an active interpreter of the pain sensation. The patient filters nerve sensations from the body through cultural, emotional, and personal lenses to identify if the pain exceeds the patient's ability to tolerate the pain and the need to access treatment. ${ }^{18}$

A number of psychological factors have been shown empirically to alter a patient's pain experience. Emotional status can have a significant impact on a patient's pain experience. Research has identified that depression and chronic pain share many of the same serotonergic pathways and are a frequent comorbidity. ${ }^{19}$ Even brief mood states can have a significant impact on pain tolerance such that a 5-minute induced mood state (positive or negative) can alter pain tolerance. ${ }^{20}$ Emotional catastrophizing is strongly associated with increased reports of pain and decreased pain tolerance. ${ }^{21}$ Feelings of pain-related self-efficacy can improve pain tolerance. ${ }^{22}$ Patients who feel more in control of their pain and have more coping skills with which to tolerate pain decrease their negative affect related to pain. In essence, the messages patients give themselves about their ability to cope with a certain level of pain become a self-fulfilling prophecy. These issues are best addressed with a pain psychologist to help patients develop their psychosocial pain-coping skills. Through psychotherapy, patients can acquire the pain coping skills necessary to increase their ability, and their confidence in that ability, to tolerate pain. In turn, reliance on pharmacotherapy is likely to decrease.

\section{Diagnostic issue: comorbid addiction and pain}

The prevalence of opioid addiction in chronic nonmalignant pain patients have been reported to vary from none in some studies up to $50 \%$, and in cancer patients up to $7.7 \%$ depending on the subpopulation studied and the criteria used. Unfortunately, in the research literature, the concept of "addiction" is often intertwined with what is better referred to as "aberrant drug-related behaviors". Aberrant drug-related behaviors may be red flags, but do not by themselves indicate the presence of addiction, which is defined as seeking the psychological effects of the drug. Aberrant drug-related behaviors can also be indicative of iatrogenic drug-seeking behaviors or diversion, among other possibilities. The risk of addiction to opioid analgesics needs to be thoroughly evaluated when initiating long-term opioid treatment. Only some screening tools like the Pain Medicine Questionnaire ${ }^{23}$ have been thoroughly validated. The risk of developing behavioral problems with chronic opioid analgesic therapy varies. While some researchers estimate that up to $24 \%$ of patients with chronic pain develop aberrant drug-related behaviors, ${ }^{24}$ others estimate that these behaviors are higher $(50 \%) .{ }^{25}$

The commonly used Diagnostic and Statistical Manual of Mental Disorders Fourth Edition criteria may overestimate the problem by using the criteria of tolerance and withdrawal. Using varying terms for the evaluation of addiction, such as drug-seeking behavior, addictive behavior, and abuse behavior can be misleading. Therapeutic dependence is another concept that may be present in chronic pain patients receiving adequate relief by opioids. These patients tend to hoard opioid analgesics to ensure that they continue to obtain adequate pain control by building up a personal reserve of opioids. ${ }^{26-28}$

Prospective studies using appropriate and thoroughly validated criteria are needed in order to make precise conclusions because estimates of addiction problems among chronic nonmalignant pain patients on long-term opioid treatment have been found to vary significantly. Some patients, especially those on short-acting opioids, may suffer from recurrent subtle withdrawal, which can be manifested as increased pain. ${ }^{29}$ It may be difficult to differentiate between the primary pain and the pain resulting from opioid withdrawal. Patients who increase opioid doses for pain relief may actually be treating their withdrawal phenomenon. ${ }^{30}$ To assist clinicians in diagnosing addiction in the context of treatment with opioid analgesics, Portenoy ${ }^{31}$ suggested a set of criteria that may be useful for this purpose. They recommended assessment of: manipulation of the treating physician or medical system for the purpose of obtaining additional medication; acquisition of medication from other medical or nonmedical sources; the tendency to hoard medications or to sell; and unapproved use of other drugs, such as alcohol and other sedatives/hypnotics during opioid therapy. For example, Dunbar and Katz ${ }^{32}$ assessed the prevalence of six behavioral criteria of 20 opioid-treated patients with chronic pain and addiction problems. They found that unauthorized dose escalation, frequent telephone calls, receiving opioids from other providers, losing the prescription, multiple reported drug allergies, and patient resistance to changing opioid medications were well correlated with a 
diagnosis of addiction made during the course of therapy by the patient's pain physician.

\section{Assessment of pain}

Pain is difficult to assess, particularly in the context of addiction, where other multiple factors may be driving elevated or suppressed reports of pain. Therefore, the commonly used $0-10$ pain scale is a good start. However, it is not enough to base pain treatment on this single self-reported pain measure, particularly if the prescriber has concerns about potential opioid misuse.

Instead, a functional assessment of pain and pain management is a more objective and reliable means to help patients address their pain management goals. This type of assessment should be used in the first meeting with a prescriber, and may be useful if assisted by a pain psychologist. In this form of assessment, the patient and provider identify areas in a patient's life that have been negatively impacted by pain management. The provider and patient would then list three goals that the patient would be able to accomplish if they experienced less pain. In this treatment modality, the provider and patient do not wait until the patient is pain-free to begin behavioral activation, but it occurs on the first visit. The patient's ability to accomplish those goals then indicates if the prescribed pharmacological treatment was helpful or if the side effects decreased the patient's ability to accomplish the goals. With each appointment, the patient and provider assess the patient's ability to complete the goals established at the previous appointment. No dosage increase is made without the patient showing progress in meeting their objectives at the previous level. This changes the entire focus of the treatment plan, ie, rather than focusing on the patient being pain-free, the focus is on helping the patient return to his/her daily activities. The return to daily activities will have the secondary impact of counteracting many mental and physical comorbidities of pain, such as depression, social isolation, and weight gain.

\section{Pharmacological treatment}

Pharmacological treatment for opiate addiction in the context of treating chronic pain is a challenging endeavor. An initial comprehensive assessment of each individual case may help design a tailored treatment plan that balances effective pharmacological treatment for both addiction and pain (see Table 1). Recent reformulations of some opioid analgesics

Table I Analgesic agents

\begin{tabular}{|c|c|c|c|}
\hline Agent & Class & $\begin{array}{l}\text { Mechanism } \\
\text { of action }\end{array}$ & $\begin{array}{l}\text { Miscellaneous } \\
\text { facts }\end{array}$ \\
\hline Morphine & Opiate & MOR agonism & \\
\hline Codeine & Opiate & MOR agonism & $\begin{array}{l}\text { Analgesia due to CYP 2D6 metabolism to } \\
\text { morphine (slow and rapid metabolizers) }\end{array}$ \\
\hline Fentanyl & Opioid & MOR agonism & Potent; associated with chest wall rigidity \\
\hline Hydrocodone & Opioid & MOR agonism & Coformulated with acetaminophen $\left(\right.$ Vicodin $\left.^{\circledR}\right)$ \\
\hline Oxycodone & Opioid & MOR agonism & $\begin{array}{l}\text { Coformulated with acetaminophen }\left(\text { Percocet }^{\circledR}\right) \\
\text { extended-release formulation }\left(\text { Oxycontin }{ }^{\circledR}\right)\end{array}$ \\
\hline Methadone & Opioid & MOR agonism & $\begin{array}{l}\text { Long-acting oral agent ( }>12 \text { hours) } \\
\text { associated with QTc prolongation }\end{array}$ \\
\hline Buprenorphine & Opioid & MOR agonism & $\begin{array}{l}\text { Coformulated with naloxone }\left(\text { Suboxone }{ }^{\circledR}\right) \text {; } \\
\text { long-acting and slow time to receptor } \\
\text { dissociation }\end{array}$ \\
\hline Tramadol & Opioid & $\begin{array}{l}\text { MOR agonism } \\
\text { vs unknown }\end{array}$ & Associated with seizures \\
\hline Duloxetine & SNRI & Unknown & Possible serotonin syndrome \\
\hline Pregabalin & Anticonvulsant & $\begin{array}{l}\text { Voltage-gated calcium } \\
\text { ion channel binding }\end{array}$ & \\
\hline Gabapentin & & Unknown & \\
\hline $\begin{array}{l}\text { Milnacipran } \\
\text { Sodium oxybate }\end{array}$ & SNRI & NMDA receptor antagonist & \\
\hline $\begin{array}{l}\text { Naltrexone } \\
\text { (low-dose) }\end{array}$ & Opioid & $\begin{array}{l}\text { Opioid receptor competitive } \\
\text { antagonist }\end{array}$ & \\
\hline Pramipexole & $\begin{array}{l}\text { Dopaminergic } \\
\text { agent }\end{array}$ & D2, D3, D4 receptor binding & \\
\hline Delta-9-THC & Cannabinoid & Cannabinoid receptor agonism & \\
\hline
\end{tabular}

Abbreviations: CYP, cytochrome P450; MOR, $\mu$ opioid receptor; NMDA, N-methyl-D-aspartate; SNRI, serotonin-norepinephrine reuptake inhibitor; QTc, corrected QT interval. 
approved by the US Food and Drug Administration (FDA), ie, OxyContin, can potentially reduce the misuse of oral medications by crushing or creating intravenous preparations. ${ }^{33}$

Most patients with chronic pain will already be treated with an opioid analgesic, and the current clinical strategies to treat this comorbidity are frequently geared towards conversion to a long-acting $\mu$ agonist treatment such as methadone, treatment with a partial $\mu$ agonist such as buprenorphine, discontinuation of opioid agonist treatment when opioid-induced hyperalgesia develops, and to minimize the diversion.

\section{Opioid analgesics}

Opiates refer to naturally occurring products that come directly from the opium poppy, such as morphine, codeine, and thebaine. ${ }^{34}$ Opioids are agents that bind to central and peripheral opioid receptors or produce clinical effects like those of natural opium (eg, mimicking opiates). In part, these $\mathrm{G}$ protein-coupled receptors may regulate analgesia via a neurotransmitter (eg, gamma aminobutyric acid) and substance $\mathrm{P}$ inhibition. ${ }^{35-37}$ The principle opioid receptors include the $\mu$ opioid receptor, the $\kappa$ opioid receptor, the $\delta$ opioid receptor, and the opioid receptor-like receptor. ${ }^{36,38}$ Other poorly characterized opioid receptors include $\varepsilon, \imath, \lambda$, and $\zeta .{ }^{36}$ Anatomic location and receptor specificity determine the type and extent of the manifested clinical effect. For example, $\mu$ opioid receptors in the brain and gut are responsible for analgesia and gastrointestinal dysmotility, respectively. However, respiratory depression may result from multiple receptors located both centrally and peripherally. ${ }^{37,39-41}$

Furlan et $\mathrm{al}^{42}$ conducted a meta-analysis of opioids for chronic noncancer pain to assess the efficacy of this treatment. The analysis included 41 trials involving 6019 patients, where $80 \%$ of the patients had nociceptive pain, $12 \%$ had neuropathic pain, $7 \%$ had fibromyalgia, and about $1 \%$ had mixed origin pain. The medications that had been evaluated in these trials included tramadol, propoxyphene or dextropropoxyphene, codeine, oxycodone, and morphine. Interestingly, the average duration of treatment was 5 weeks, with $33 \%$ of participants dropping out in the opioidtreated group compared with $38 \%$ of participants in the placebo groups. The magnitude of pain reduction with opioid analgesics compared with placebo was found to be moderate and the improvement in functional outcomes was even smaller. Eight trials that compared opioids with other analgesics showed that opioids did not differ significantly from nonopioid analgesics for pain treatment. Interesting, opioids were significantly worse than nonopioid analgesics on functional improvement measures. Despite the empirical evidence that opioid analgesics are not highly efficacious for the control of chronic pain and for functional recovery, physicians continue to prescribe them. This leads to a number of interesting points of discussion that should certainly be addressed in a different venue.

\section{Risk and adverse effects of opioids}

The sine qua non of opioid toxicity is respiratory depression, and other effects, such as miosis, decreased bowel motility, and mental status depression, are also problematic side effects. Patients with severe respiratory depression require supportive care, but antidotal treatment for opioid overdose is pharmacologically directed toward antagonizing central nervous system opioid receptors. Naloxone $\left(\operatorname{Narcan}^{\circledR}\right)$ is the parenterally available opioid receptor antagonist used in clinical practice to reverse the symptoms of opioid-induced respiratory depression rapidly. ${ }^{43}$ Carefully titrated doses of naloxone may reverse opioid toxicity without inducing symptoms of opioid withdrawal, even in the opioid-dependent patient. Assistance in titrating naloxone dosing may be obtained from local toxicology consultation services or by contacting a poison control center.

Moore and McQuay ${ }^{44}$ conducted a systematic review of 34 trials involving a total of 4212 patients and provided information on adverse events related to opioid analgesic use in treating noncancer pain. The most frequent side effects related to treatment with opioid analgesics compared with nonopioid analgesics were nausea, constipation, and somnolence. Eisenberg et $\mathrm{al}^{45}$ also reported that treatment involving the use of opioid analgesics for neuropathic pain when compared with treatment with placebo showed higher rates of nausea, constipation, drowsiness, dizziness, and vomiting. Endocrine abnormalities, such as hypogonadism and erectile dysfunction, may also be associated with opioid treatment. ${ }^{46}$ Opioid treatment may be associated with impaired neuropsychological performance, mainly in reaction times, psychomotor speed, and working memory. ${ }^{25}$ Prolonged treatment with opioid analgesics commonly results in the development of opioid-induced hyperalgesia that occurs when the balance between antinociceptive and pronocioceptive systems are upregulated after opioid exposure, with enhanced vulnerability to experience pain. ${ }^{47}$

\section{Opiates}

Morphine is a natural product that produces effective analgesia following multiple routes of administration. ${ }^{48}$ Decreased analgesia observed following enteral absorption 
is due to first-pass metabolism that is absent following parenteral delivery. Hepatic metabolism results in morphine-3-glucuronide and morphine-6-glucuronide, and these metabolites are renally excreted. ${ }^{49}$ Analgesia is a consequence of $\mu$ opioid receptor agonism centrally and peripherally. ${ }^{48,50}$

Codeine, the biosynthetic precursor to morphine, is another natural product used in clinical practice. Codeine has no intrinsic analgesic properties; its demethylation to morphine via cytochrome P450 (CYP) 2D6 explains the absence of clinical effects in specific subpopulations with CYP2D6 deficiency. ${ }^{51}$

\section{Fentanyl}

Fentanyl is a highly potent, short-acting synthetic opioid. ${ }^{52}$ It exerts clinical effects following multiple routes of administration, including transdermal patches, oral lollipops, and dissolving lozenges, as well as intravenous administration. Fentanyl has found extensive use in the management of chronic pain; extended-release formulations are often used to treat persistent symptoms, while breakthrough pain may be treated with "lollipop" or lozenge formulations. Fentanyl has a high abuse potential and has been strongly associated with death following misuse. ${ }^{53}$

\section{Hydrocodone and oxycodone}

Hydrocodone and oxycodone are both synthetic opioids with intermediate durations of action. Hydrocodone is most commonly available orally when coformulated with acetaminophen. Oxycodone can be formulated by itself as a short-acting medication or as a controlled-release preparation (OxyContin) and can also be coformulated with nonsteroidal anti-inflammatory agents. Oxycodone has a high potential for abuse, has been heavily diverted to illicit purposes, and has been associated with many opioid-related overdoses. ${ }^{54}$ Because oxycodone can be abused by ingestion, insufflation, and parenteral injection, the FDA recently approved a reformulation of OxyContin that mitigates its abuse potential. ${ }^{33}$

\section{Methadone}

Methadone is a synthetic, potent $\mu$ opiate receptor agonist and is likely the best candidate to achieve the two goals of treating pain and addiction. Methadone is $80 \%$ bound to blood proteins and has a long elimination half-life (24-36 hours), facilitating its use for once-daily agonist maintenance in the treatment of addiction. ${ }^{55}$ Dividing the daily dose of methadone may help achieve better analgesia and should be considered for patients with comorbid chronic pain and addiction. ${ }^{56}$ The methadone maintenance dose for substitution therapy is usually 60-150 mg per day. These dosages are usually higher among patients with chronic pain, and doses up to $300 \mathrm{mg}$ have been reported. ${ }^{57,58}$

High doses of methadone ( $>100 \mathrm{mg} /$ day) have been associated with cardiac side effects, including QT interval prolongation. ${ }^{59,60}$ However, a study by Martell et al ${ }^{61}$ showed that, regardless of the level of methadone dose, there was a mean 10.8 millisecond increase in the QTc interval in patients treated with methadone during induction and stabilization $(P<0.001)$, but none of these patients had a clinically significant increase in the QTc interval (40 millisecond increase or over 500 milliseconds). In addition, a study that evaluated 104 patients treated with methadone (median $110 \mathrm{mg} /$ day, range $20-1200 \mathrm{mg} /$ day) for comorbid pain and addiction showed that a third of these patients had a prolonged QTc, but none had a prolongation over 500 milliseconds, suggesting a minimal cardiac risk among this patient population. ${ }^{62}$

Based on these concerns about QTc interval prolongation associated with methadone treatment, a group of experts issued five recommendations: ${ }^{60}$ patients should be informed about the risk of arrhythmia; history-taking should include questions about structural heart disease, arrhythmia, and syncope; an electrocardiogram should be performed before treatment with methadone in all patients to measure the QTc interval, and should be followed with an electrocardiogram after 30 days of starting methadone and thereafter annually, repeating the electrocardiogram when patients need a dosage of methadone over $100 \mathrm{mg} /$ day or present with syncope or seizures; in patients with a QTc interval over 450 milliseconds but less than 500 milliseconds, there is a need to increase monitoring and to review potential risks and benefits of continuing treatment with methadone, and when QTc interval is greater than 500 milliseconds there is a need to reduce or discontinue the dose of methadone, and to review potential contributing factors that may be worsening the condition, like hypokalemia; and review potential drug-drug interactions between methadone and other drugs that either increase QTc or increase the level of methadone.

Methadone has been used mostly as a maintenance medication for opioid-addicted individuals. In addition to functioning as a full agonist at the $\mu$ opioid receptor, methadone is also an antagonist of the N-methyl d-aspartate receptor, which explains the decreased development of tolerance. 
It should be noted that patients positive for human immunodeficiency virus being treated for comorbid pain and addiction with methadone will most likely need dose adjustment due to the interaction with CYP3A4. ${ }^{57}$ While nevirapine and efavirenz have both been reported to reduce plasma methadone levels and induce opioid withdrawal symptoms, delavirdine may increase methadone concentrations, but this effect is unlikely to be clinically significant in most cases. Finally, methadone may increase plasma concentrations of zidovudine. ${ }^{63}$

Methadone is a long-acting opiate that can be substituted for short-acting opiates like heroin, morphine, oxycodone, hydromorphone, and hydrocodone. Due to cross-tolerance effects, methadone effectively reduces the euphoric and reinforcing effects of further abuse of short-acting opioids. Further, the longer half-life of methadone reduces fluctuations in opiate receptor stimulation, decreases withdrawal symptoms, and decreases the probability of relapse. Dividing the methadone dose prolongs the analgesic effect of methadone while reducing the reinforcing effect of repeated doses, which can translate into an effective treatment for comorbid pain and addiction. Methadone maintenance programs continue to be the most structured and effective treatment for opiate dependence by decreasing intravenous drug use and the risk of transmissible infections. ${ }^{64,65}$

Unfortunately, these methadone treatment programs are not authorized in the US to treat chronic pain patients. The major limitation of methadone maintenance programs in this context is that they are only licensed to treat opiate addiction, and dosage adjustment is only possible in order to stabilize opioid craving, withdrawal, or sedation. While in many ways this restriction may be seen as appropriate given the lack of expertise in pain management, this limitation can be resolved by integrating treatment with primary care or by blending pain management training into the curriculum of addiction psychiatry or addiction medicine programs.

Another limitation in methadone treatment programs is the regulatory delay of take-home methadone doses, based on complete abstinence, but for patients with comorbid chronic pain this delay would not allow for divided doses, at least during the initial phase of treatment. Patients with chronic pain receive a once-daily dose of methadone for their opiate addiction in these programs, although it is likely that they will still need short-acting opioids for breakthrough pain. Ideally, these patients would be better served in a pain clinic that could simply divide the same methadone dose, which would likely control the pain without the need of additional opioid medications.
Methadone maintenance in physicians' offices or "medical maintenance" is an alternative format for take-home methadone doses that has the potential of expanding methadone maintenance services for those individuals who are psychosocially stable. ${ }^{66-68}$ This could potentially include treatment of those with additional chronic pain and can translate in resolving both major limitations to methadone maintenance treatment of comorbid pain and addiction. However, take-home doses have their own problems in these settings, including diversion of methadone to the black market and fatalities due to accidental ingestion by minors. ${ }^{69}$ Conversely, treatment of these patients outside of substance abuse treatment facilities generates another set of problems, such as lack of expertise in psychosocial interventions. Additionally, treatment providers outside of substance abuse clinics are less likely to understand the motivational impact of frequent urine samples. Additionally, the few nonaddiction treatment providers who do integrate urine samples into their treatment plan, may not be aware of the need to use toxicology results immediately in the therapeutic context to motivate change in behavioral patterns while presenting the results in a nonjudgmental way to help build an enduring therapeutic alliance. Mostly, patients with addictive disorders respond well to these interventions when they are framed in the context of treatment in a nonpunitive manner. The paucity of training in pain and addiction makes treatment in conventional settings challenging for physicians.

\section{Buprenorphine}

Buprenorphine is a high-affinity partial $\mu$ opioid agonist that is used worldwide either alone or as a combination tablet of buprenorphine and naloxone for substitution therapy. ${ }^{70}$ This combination was developed to reduce the risk of diversion to illicit intravenous use, because such administration would precipitate severe withdrawal in an opiate-dependent individual. Buprenorphine, and its metabolite norbuprenorphine, achieve steady-state concentrations in approximately $8-10$ days. $^{71}$ As a partial agonist, buprenorphine has minimal risk of overdose from respiratory depression, and higher doses of buprenorphine can increase the duration of its effects. Because of its long action, buprenorphine can be effectively administered in alternate day dosing and as infrequently as three times per week. ${ }^{72,73}$ Buprenorphine has a ceiling effect on its agonist activity, which may also limit its abuse liability ${ }^{74,75}$ and can lead to low toxicity even at high intravenous doses. ${ }^{76,77}$ Buprenorphine is thought to exhibit a ceiling 
effect on respiratory depression at therapeutic dosing, but the impact on supratherapeutic doses of buprenorphine has not yet been established. Apnea has been observed following polysubstance use (most commonly with misused benzodiazepines) and in children, and may occur following overdose of buprenorphine itself.

Buprenorphine has the general structure of morphine but differs from morphine in significant ways, both pharmacologically and clinically. A number of long-term studies have shown effective, long-lasting analgesia in moderate to severe cancer and noncancer pain, including neuropathic pain, with a low incidence of constipation, nausea, dizziness, and tiredness.

In 2007, a panel of experts specializing in palliative care and pain treatment ${ }^{78}$ reviewed the clinical experience with transdermal buprenorphine and other analgesics, and considered that transdermal buprenorphine was a valuable treatment for cancer pain, including its neuropathic components. Buprenorphine has been described to exert an antihyperalgesic effect. The dose range of 35-140 $\mu \mathrm{g}$ per hour was considered adequate to achieve sufficient pain relief in most patients, although higher doses provided improved pain relief when a slow titration was used. Because of the high affinity to the $\mu$ receptor and its ceiling effect, treatment with buprenorphine-naloxone (Suboxone ${ }^{\circledR}$ ) maintenance therapy may pose at least theoretical problems in managing pain in these comorbid patients. ${ }^{79}$ However, the pharmacological profile of buprenorphine, as a partial $\mu$ opioid agonist and a $\kappa$ opioid antagonist, makes it an excellent medication for the treatment of chronic pain when utilizing a 72-hour transdermal delivery system designed to release buprenorphine continuously at $35,52.5$, or $70 \mu \mathrm{g}$ per hour. ${ }^{80}$ Buprenorphine at lower dosages $(0.3-0.6 \mathrm{mg})$ than those used for the treatment of opioid addiction (12-32 mg) may have excellent analgesic effects, but may not have appropriate efficacy for opiate addiction. Conversely, because buprenorphine binds strongly to opioid receptors, the use of supplementary opioids for analgesia is difficult. Therefore, for additional analgesia, or breakthrough pain, it may be necessary to force a change of treatment with buprenorphine to methadone for maintenance medication.

Patients treated with buprenorphine for addiction can usually be stabilized with sublingual doses of 12-16 mg per day. Ling et $\mathrm{al}^{81}$ showed that patients maintained on buprenorphine 8-16 mg per day during a 16-week trial were more likely than patients maintained on buprenorphine $1 \mathrm{mg}$ per day to remain in treatment. In another study, heroin-dependent patients without psychiatric or substance use comorbidities were successfully treated with buprenorphine at $24 \mathrm{mg}$ on Monday and Wednesday, and $36 \mathrm{mg}$ on Friday. ${ }^{82}$

\section{Tramadol}

The mode of action of tramadol is not completely understood, but it appears to exert an analgesic effect through binding to the $\mu$ opioid receptor as a partial agonist. It also inhibits the reuptake of serotonin and norepinephrine, and can cause serotonin syndrome. Furthermore, tramadol is a proconvulsant and has been associated with seizures even at therapeutic levels. Tramadol has proven efficacy in fibromyalgia, osteoarthritis, and neuropathic pain. Because tramadol is an unscheduled drug, clinicians may not be aware of its opioid effect and potential for abuse. A randomized trial in patients suffering from chronic noncancer pain compared the abuse potential of tramadol, nonsteroidal anti-inflammatory drugs, and hydrocodone. ${ }^{23}$ The abuse liability over 12 months was $0.5 \%-2.5 \%$ for the nonsteroidals, $0.7 \%-2.7 \%$ for tramadol, and $1.2 \%-4.9 \%$ for hydrocodone. In another study, McDiarmid et $\mathrm{al}^{83}$ found that tramadol showed a milder degree of physical dependence, but also showed craving during discontinuation. Daily recommended doses of tramadol should not exceed $400 \mathrm{mg}$. During discontinuation, gradual dose reduction is recommended in elderly populations, and in those with renal and hepatic impairment. ${ }^{84}$

\section{Discontinuation of opioid agonists}

The decision to discontinue methadone treatment for opioid addiction after a determined length of maintenance is highly controversial, given the high risks of relapse to previous patterns of maladaptive drug use and the associated morbidity and mortality. ${ }^{85}$ This also applies to patients treated for chronic pain who may be stable and responding well to pain management with opioid medications. However, if opioidinduced hyperalgesia develops in the context of treatment for both disorders, it may be necessary to consider discontinuation. The efficacy of long-term treatment for chronic pain with opioids is not clearly supported. ${ }^{24}$ Therefore, differentiating between increased tolerance vs sensitization to hyperalgesic opioid effects is a key element in the management of these complications. ${ }^{86}$ An increase of the dose will reduce pain in the context of increased drug tolerance, but the same dose increase can potentially aggravate pain in the context of sensitization or hyperalgesia. A clarified diagnosis helps to individualize treatment and to offer a tailor-made management plan, with close monitoring and additional psychotherapy to support both pain reduction and relapse prevention. 


\section{Nonopioid medications used as analgesics}

The long-term trajectory of chronic pain that may have promoted the development of opioid addiction can be prognostically improved if nonopioid agents are effectively used early in treatment. Some of these medications can be utilized for breakthrough pain, hyperalgesic rescue, or as an adjunct to opioid treatment. Most studies support adjunctive medication usage in both neuropathic and fibromyalgic pain.

\section{Gabapentin}

Gabapentin was initially marketed as an anticonvulsant medication, but was later found to be useful in the treatment of pain. A recent study showed that gabapentin could be an option in the conservative management of acute or chronic radicular pain caused by lumbar disc herniation or lumbar spinal stenosis. ${ }^{87}$ In another study, Ucak et al ${ }^{88}$ compared gabapentin with placebo and showed that gabapentin significantly reduced the intensity of pain and tramadol consumption relative to placebo when used in the early postoperative period after coronary artery bypass graft surgery. The use of gabapentin combined with donepezil as an adjunct for the treatment of neuropathic pain showed a 3-4-fold increase of analgesic effect when compared with treatment using gabapentin alone. ${ }^{89}$ Taken together, these results suggest that gabapentin may have a role in the treatment of pain.

\section{Pregabalin}

Originally developed as an anticonvulsant, pregabalin became the first FDA-approved drug for the treatment of fibromyalgia in June 2007. This adjuvant analgesic exerts its therapeutic effects by binding to and decreasing the activity of the alpha-2-delta subunit of the voltage-gated calcium ion channel, which plays an important role in nociceptive hypersensitivity. Presynaptic binding to voltage-gated calcium ion channels results in a decrease in excitatory neurotransmitter release of neurochemicals, such as substance $\mathrm{P}$, calcitonin, and glutamate. ${ }^{90}$

Pregabalin has been found to be effective in both neuropathic pain and fibromyalgia. Its efficacy in the treatment of fibromyalgia has been evaluated in four randomized, double-blind, placebo-controlled trials. ${ }^{90-93}$ The results of these studies have consistently shown improvement in pain, fatigue, and sleep difficulties, with no major side effects. Pregabalin administered at $450 \mathrm{mg} /$ day in three divided doses was found to reduce pain scores significantly and increase the responder rate compared with placebo during an 8-week study, and these changes were independent of improvements in levels of anxiety or depression. ${ }^{90}$

No pharmacokinetic interactions were seen during the coadministration of pregabalin and oxycodone, lorazepam, or ethanol. ${ }^{94,95}$ Additive effects on cognitive and gross motor functioning were observed, suggesting a need for dose reduction when combined with benzodiazepines or alcohol. Dose reduction is necessary in renal dysfunction, with a need for monitoring of creatinine clearance. ${ }^{94,95}$ There is one report by Filipetto et $a 1^{96}$ mentioning the potential for pregabalin abuse or diversion, based on a single case of a woman who received a total of $88,500 \mathrm{mg}$ of pregabalin over a 28 -day period from different providers.

\section{Duloxetine}

Duloxetine is a serotonin-norepinephrine reuptake inhibitor that also has a low affinity for the dopamine transporter at higher doses. There have been at least five randomized, double-blind, placebo-controlled trials ${ }^{97-101}$ assessing the efficacy of duloxetine for fibromyalgia. Although duloxetine decreased pain and symptom severity of fibromyalgia in most patients, the improvements were only significant in women and independent of baseline status for major depressive disorder. In a 12-week study, Arnold et a ${ }^{98}$ examined the effect of duloxetine $60 \mathrm{mg}$ given once or twice daily vs placebo in 354 women with fibromyalgia with or without concurrent major depressive disorder. The results showed a significant improvement in pain severity and interference scores, and the effects on pain reduction were independent of the effect on mood and presence of major depressive disorder. In another study, Arnold et al ${ }^{102}$ conducted a pooled analysis of four studies, with $26 \%$ of the sample diagnosed with comorbid major depressive disorder. These participants were randomly assigned to received duloxetine $60-120 \mathrm{mg} /$ day or placebo, and the results showed that those treated with duloxetine had a better reduction of mean 24-hour pain severity, greater reduction of fibromyalgia symptoms, and more improvement in mood, quality of life, and function relative to placebo.

The side effects of duloxetine are generally dose-related and time-limited. According to Greden et al, ${ }^{103}$ clinical trials to date have demonstrated that duloxetine is safe and well tolerated in the dose range of $20-120 \mathrm{mg} /$ day for up to 1 year. ${ }^{100}$ The side effects often reported are nausea, dry mouth, hyperhidrosis, constipation, insomnia, dizziness, headache, and fatigue, which led to a premature discontinuation rate of $21 \%$ in these trials. The CYP1A2 inhibitor, thioridazine, should not be coadministered with duloxetine due to the risk of serious ventricular arrhythmias and sudden death. ${ }^{94,95}$ There 
have been no reported studies to date of the abuse potential with this medication.

\section{Milnacipran}

Milnacipran is a serotonin-norepinephrine reuptake inhibitor approved for the treatment of fibromyalgia. Milnacipran is devoid of action at a large array of receptors, but does appear to be a noncompetitive N-methyl d-aspartate antagonist. ${ }^{104}$ Functional magnetic resonance imaging studies showed an increase in activity in the thalamus, caudate nucleus, cingulum, anterior insula, and amygdala following administration of milnacipran $100 \mathrm{mg}$ twice daily. ${ }^{105}$ Nagaoka et al ${ }^{106}$ found that milnacipran improved both pain at 8 weeks and depression at 4 weeks. Importantly, only patients who were not depressed at the end of the study exhibited significant improvements in visual analog score for pain. In a European study, Branco et $\mathrm{al}^{107}$ found that milnacipran $200 \mathrm{mg}$ /day for fibromyalgia showed an overall improvement in pain and functioning relative to treatment with placebo. Yet another multicenter study in the US showed that significant reductions in pain occurred with twice-daily but not with once-daily dosing. ${ }^{108}$

Milnacipran is well tolerated, but has an adverse event profile of nausea, headache, tachycardia, and hypertension typical of the serotonin-norepinephrine reuptake inhibitor class. The CYP system is not involved in its metabolism, and therefore drug-drug interactions are unlikely. ${ }^{94,103}$

\section{Tricyclic antidepressants}

Tricyclic antidepressants are also widely used in the treatment of chronic pain, particularly neuropathic pain. ${ }^{109}$ An adequate trial is usually 6-8 weeks, although the analgesic affects of tricyclic antidepressants often occur faster than the antidepressant effects. There is less evidence to support its use in musculoskeletal pain or in inflammatory rheumatic diseases. Despite their analgesic properties, tricyclic antidepressants are also unfortunately well known for their negative effects, with $6 \%-86 \%$ of patients reporting adverse effects, including dry mouth, constipation, blurred vision, cognitive changes, and tachycardia due to the anticholinergic activity of these agents. ${ }^{110}$ Patients may also discontinue due to adverse effects related to sedation and weight gain. There are a number of excellent indepth reviews of the analgesic properties of antidepressants that can be explored more indepth than in this venue. ${ }^{109}$

\section{Emerging treatments}

A series of emerging therapies for pain that include dopamine agonists, N-methyl-D-aspartate antagonist receptor antagonists, sodium oxybate, low-dose naltrexone, pramipexole (nonergoline D2, D3, and D4 dopamine receptor binding) and delta-9-tetrahydrocannabinol, have proven effective in preliminary trials. ${ }^{94}$ The therapeutic promise of the $\kappa$ opioid receptor agonists has also been recently revived by some preclinical trials, as evident from some drugs initiating $\mu$ opioid signaling such as methadone and fentanyl, that recruit arrestin, promote internalization of the receptor, and reduce development of tolerance. Morphine does not do this. With the new concept of biased agonism, functional selectivity, and ligand-directed signaling, ${ }^{111}$ different agonists binding to the same receptor can produce different actions, and an analgesic $\kappa$ opioid that is not involved in arrestin recruitment might not produce dysphoria. Such a novel ligand in combination with a peripherally restricted $\kappa$ opioid antagonist to block the constipating and diuretic effects, might result in the long-sought nonaddictive designer opioid analgesic. ${ }^{112}$ Recently another molecular target for treating chronic neuropathic pain was identified. Protein kinase $\mathrm{M}$ zeta, an atypical isoform of protein kinase $\mathrm{C}$, appears to maintain persistent changes in the anterior cingulate cortex induced by neuropathic pain, and selective inhibitors of protein kinase $\mathrm{M}$ zeta could treat this condition. ${ }^{113}$

\section{Psychosocial approaches to treatment}

Psychosocial factors should be considered in any assessment and treatment of comorbid opioid misuse and pain. Psychosocial factors may be one of our strongest weapons against abuse and misuse of opioids. Empirically validated treatments for this comorbidity are in the early stages of development. We will review the literature on what treatment approaches are individually validated for the treatment of pain or addiction, and where there is empirical evidence to support their use in treatment of comorbid pain and addiction.

\section{Motivational interviewing}

Clinicians who work with pain patients and suspect opioid misuse should be familiar with the techniques of motivational interviewing. During a motivational interview, clinicians draw on the transtheoretical stages of change developed by Prochaska and Diclemente ${ }^{114}$ to assess whether or not patients are willing to consider the negative effects of opioids on their lives, as well as their willingness to engage in other forms of therapy to reduce their reliance on opioid medications effectively. By assessing patients with possible comorbid pain and addiction using this approach, it provides patients with an empathetic, nonjudgmental platform to discuss the 
patient's concerns about their medication use/abuse and to identify if their use of opioids allows them to meet their life goals. ${ }^{115}$ For those patients willing and able to identify the negative impact of opioids on their lives, referral to health psychologists (particularly those specializing in pain management), physical therapists, and family system therapists would be appropriate.

\section{Cognitive behavioral therapy}

Using goal-focused integrated cognitive behavioral therapy, pain management, and opioid misuse treatment would focus on patient goals that link across both issues. Because the primary goal is to return the patient to as close to normal functioning as possible, a shared goal can be used as the focus of therapy sessions. Common subgoals to both pain ${ }^{116}$ and substance abuse ${ }^{117}$ include: increased feelings of pain and craving self-efficacy; decreased reliance on chemical substances for relief; reduced anxiety and depression; increasing environmental stimulation to reduce focus on pain or substance use from boredom; resuming pleasant hobbies and activities; increased distress tolerance (eg, cravings, pain); and increased social support for healthy activities. Research suggests that cognitive behavioral therapy utilizing these or similar tools can be effective in reducing opioid use, even in the context of chronic pain. A 3-week intensive behaviorally-based pain program on opioid use showed that, at 18-month follow-up, 123 patients not only used significantly less opioid medication ( $72 \%$ vs $24 \%$ ), but also reported significantly lower pain levels (8.2/10 vs 4.2/10). ${ }^{118}$ Cognitive behavioral therapy and derivatives of cognitive behavioral therapy (such as acceptance and commitment therapy) are arguably the primary backbone of all current psychotherapy for either pain or addiction. Therefore, it is expected that any multidisciplinary treatment for comorbid pain and addiction would include a health psychologist trained in advanced cognitive behavioral therapy techniques.

\section{Behavioral shaping}

Used hand-in-hand with the previously described assessment of functioning, behavioral shaping can be used as a basis for helping patients resume a healthy lifestyle, and is arguably one of the most established treatments for chronic pain. ${ }^{119}$ As the patient and physician relationship develops and it becomes clear that the patient is expected to participate in his/ her care (and not just be a passive recipient of medications), behavioral shaping can be a very powerful tool. Patients set small weekly or monthly behavioral goals that will help them move towards a healthy lifestyle. These are identifiable and measurable goals that can be monitored in the clinician's office. As the patient re-engages with his/her daily activities he/she should be encouraged by the clinician and will likely be rewarded for increasing activities via increased social support, positive reinforcement by family members, more positive self-esteem, and a reduction in pain. As the patient's focus shifts to external stimuli rather than maintaining a focus on their pain in the absence of any cognitive distractors, their pain experience will decrease. True behavioral shaping (or operant conditioning) includes material rewards as well (eg, tokens that can be redeemed for goods), and can be integrated into treatment plans for patients who are initially less intrinsically motivated. This technique in essence uses both operant conditioning and cognitive dissonance. Patients are rewarded (with materially or nonmaterial rewards) for "good" behaviors that they then desire to repeat. As patients continue to engage in positive behaviors, they also transfer the desire to engage in the behavior from "earning a reward" to an internally motivated drive. ${ }^{120}$ This has been used successfully to reduce pain reports, as well as opioid use. ${ }^{121}$ Usually this treatment is best integrated into a multidisciplinary treatment plan and should not be used as a stand-alone treatment device. $^{122}$

\section{Self-regulation therapy}

Self-regulation therapy is found under many names in the research literature, including autogenic training, relaxation therapy, biofeedback, and imagery. Meta-analyses have shown that these forms of treatment rival pain reduction rates of opioid medication. ${ }^{123}$ This form of therapy is frequently integrated with other psychosocial pain management strategies as one step to increasing patient self-efficacy. The health psychologist directing this therapy teaches patients to reduce their physiological reactivity to pain, cravings, and strong emotional states to improve the patient's control over their pain experience.

\section{Acupuncture}

In 1998, the National Institutes of Health convened a conference to review the evidence on the efficacy of acupuncture. At that time, it was recognized that sufficient evidence existed to endorse the complementary use of acupuncture to treat (among other things) chronic pain and substance abuse. ${ }^{124}$ Research has been somewhat limited in treating substance misuse in the context of chronic pain, but a meta-analysis of studies of acupuncture for chronic pain suggests a minimum of six treatments is needed to see a significant change in pain reports. ${ }^{125}$ 


\section{Spirituality}

Integrating spiritual resources into treatment has been of increasing interest to researchers in the areas of both addiction and chronic pain. If patients have a faith background that can support them in reducing opioid use and improving pain management, clinicians should consider encouraging patients to use those resources. Many of those undergoing addiction treatment report that spirituality is a positive coping mechanism for them, and welcome integrating spirituality into treatment protocols. ${ }^{126}$ Prayer is one of the top paincoping strategies in the context of opioid dependence. ${ }^{127}$ Additionally, research has shown that spirituality can be a powerful mechanism for chronic pain relief, and empirically validated treatments have been developed to help patients with chronic pain increase their self-efficacy and to improve their coping with pain. ${ }^{18}$

\section{Meditation}

Meditation techniques vary widely, and include mantram, transcendental meditation, loving-kindness, yoga, and tai chi. Meditation is well supported as a treatment of both pain and opioid addiction. While there is limited empirical data on using meditation to treat comorbid pain and opioid addiction, sufficient evidence exists for individual treatment of pain ${ }^{128-130}$ and addiction ${ }^{131}$ to warrant consideration.

\section{Mindfulness}

Like for meditation, there are a large number of mindfulness techniques which may be useful in treating polysubstance addiction ${ }^{132}$ and chronic pain. ${ }^{133,134}$ However, there appears to be a lack of quality studies specifically looking at the effect of mindfulness on opiate addiction and opioid misuse. ${ }^{135}$ There is a need for more research in this area.

\section{Chronic pain support groups}

Support groups can be very helpful for some individuals with chronic pain, and these groups are readily available via the Internet or phone. Support groups provide information and strategies to manage chronic pain. In addition to learning new skills and information, individuals can gain a sense of hope that others have been able to manage their chronic pain. They are able to manage the emotional struggles and spiritual suffering that chronic pain can cause better. Support groups can be safe places to share feelings and receive nonjudgmental acceptance and positive regard. ${ }^{136}$

There are a variety of types of support groups, including in-person, phone, and Internet options. Some meetings focus on general chronic pain and others focus on pain related to specific diseases, eg, arthritis, cancer, and fibromyalgia. Meetings can be led by experts or peers with chronic pain, be structured or unstructured, and focus on providing information or social support, emotional support, or skills such as relaxation strategies. There are support groups that are modeled on the 12-step peer support model similar to Alcoholics Anonymous and other 12-step programs. Chronic Pain Anonymous is the prototype of adapting the 12-step model. Table 2 provides a list of support groups and other Internet resources that provide much more information.

The Internet is a window to many resources, including some that are very reputable and helpful, but not all. The average person now seeks information on the Internet routinely and many have had the experience of joining chat rooms, blogs, list serves, and message boards. However, there continue to be individuals who will need encouragement to consider this source of information and support. Less Internet-savvy individuals will likely need specific recommendations for Internet groups, as well as ongoing encouragement and conversation about their efforts to connect with support groups. Clinicians might consider giving out the information from Martelli et a ${ }^{137}$ who provide an introductory guide to chronic pain resources on the Internet.

Some advantages to online support groups are that there is no cost, they are easy to access, are available 24 hours and 7 days per week, and allow individuals to remain anonymous. There are advantages to in-person meetings for those individuals who prefer in-person conversations, including more indepth conversation, and a quicker sense of connection with others. Patients can benefit from discussing the options with their clinicians.

The American Chronic Pain Association has helpful information on their website to prepare individuals to participate in support groups. This organization also has a 10 -step guide available which is designed to help people deal better with their pain and improve the quality of their lives. The 10-step

Table 2 Chronic pain support groups and Internet resources

\begin{tabular}{ll}
\hline American Academy of Pain Medicine & www.painmed.org \\
American Chronic Pain Association & www.theacpa.org \\
American Pain Foundation & www.painfoundation.org \\
Chronic Pain Anonymous & www.chronicpainanonymous.org \\
Chronic Pain Support & www.chronicpainsupport.org/ \\
National Chronic Pain Outreach & support.html \\
Association & www.chronicpain.org \\
National Chronic Pain Society & www.ncps-cpr.org/ \\
& supportgroups \\
National Pain Foundation & www.nationalpainfoundation.org/ \\
& community.php \\
\hline
\end{tabular}


guide is quite different from the 12-step model of Chronic Pain Anonymous. The 10-steps include accepting the pain, getting involved in one's own health care, learning to set priorities, setting realistic goals, knowing that one has a basic right to be respected, recognizing that emotions affect physical wellbeing, learning to relax, exercising, seeing the total picture, and reaching out to share with others. ${ }^{138}$

The 12-step approach is based in spiritual healing and the power of the support group (ie, "fellowship"). The 12-step program begins by encouraging individuals to accept that their life has become unmanageable due to chronic pain (acceptance step) and that individuals are powerless to cure the physiology of the pain but do have the ability to control their reaction to the pain. The emphasis on spirituality is the cornerstone to this approach. For many with chronic pain this is very important and often not a part of traditional medical treatment. Some individuals with chronic pain are angry at their God and feel betrayed in that relationship ("Why me? How could God have allowed this to happen to me?"). The 12-step approach can ultimately be very helpful for these individuals.

In summary, clinicians should be aware of the wide range of support groups and community resources available, provide this information to patients, and include discussions and recommendations for their patients. Continuing to follow up on their interest and ability to engage in support groups is important.

\section{Diversion}

Diversion of opioid analgesics from legitimate to nonmedical use is on the increase. ${ }^{14}$ At present, prescription opioid analgesics are the most commonly abused prescription medications in the US. Drug diversion occurs at every point in the drug supply chain, ie, at the level of distribution because of theft, at the retail level with the sale of controlled substances without prescriptions, the use of stolen or forged prescriptions, theft from pharmacies or health care facilities, at the patient level with inappropriate prescribing, and the seeking of prescription drugs under false pretenses. The improper disposal, sale, or gifting of legitimately prescribed medications also contributes to the pool of diverted drugs.

People divert opioid analgesics for a variety of reasons. Although some divert drugs for monetary gain, other individuals may use the illegally acquired drugs themselves. Other nonmedical uses of prescription drugs include exploratory behavior, compulsive use, self-medicating for mood, sleep, or pain, and to alleviate abstinence symptoms. The relationship between increased opioid prescribing and the misuse of opioids is unclear. For example, prescription drug users are less likely to obtain prescription opioids for euphoria than for pain, and those who do use opioid analgesics for euphoria usually purchase these drugs from dealers. ${ }^{139}$

\section{State-level interventions to address misuse of prescription drugs}

Due to the high rates of both chronic pain and prescription drug misuse, state-level interventions have developed over the past 50 years, including requiring continuing medical education credits on these topics, providing guidelines and other resources for prescribers, and the development of prescription monitoring programs. These state-level interventions target the wide range of prescribers (see Table 3 ).

Some states have very helpful websites that provide information for prescribers. An example is the Massachusetts Pain Initiative (www.masspaininitiative.org). This website provides information and downloadable PDFs including a pain resource guide, newsletter, screening tools, and pocket pain management tool. Another state providing helpful information is Oregon (http://www.oregon.gov/OHA/OHPR/ PMC/index.shtml/), which supplies policy information and educational materials.

Washington State has an online resource guideline on the use of opioids for chronic noncancer pain. The guideline was developed by experts in the field on behalf of the state's Agency Medical Directors Group. The guideline includes other resources and tools to educate prescribers. In addition, the site has free continuing medical education credits (www. agencymeddirectors.wa.gov/). California and Oregon are examples of states that have gone beyond providing information, in that they require their prescribers to take a specific number of continuing medical education credits on chronic pain and pain management.

State prescription monitoring programs have been implemented in about $50 \%$ of states, and are being developed or considered in another $25 \%$ of states. ${ }^{140}$ These programs include prevention, intervention, investigation, and enforcement. They were developed to reduce the likelihood of drug diversion by prescribers, doctor shopping, and fraud, and to prevent unnecessary deaths and injuries associated with use

Table 3 State-level resources

\begin{tabular}{ll}
\hline Massachusetts Pain Initiative & www.masspaininitiative.org \\
Oregon Pain Management & www.oregon.gov/OHA/OHPR/PMC/ \\
Commission & index.shtml/ \\
Washington Agency Medical & www.agencymeddirectors.wa.gov/ \\
Directors Group & \\
Alliance of State Pain Initiatives & http://trc.wisc.edu/ \\
\hline
\end{tabular}


of prescription medications for pain management. Prescription monitoring programs can track data from pharmacies and provide prescribers with more complete information about patient use of controlled substances (patient activity reports). They can provide statistical reports to follow state trends and create collaborations with other state agencies and programs. In 2003, the Drug Enforcement Administration and the Department of Justice initiated a competitive grant program that attempted to encourage more states to create prescription monitoring programs. At that time, there were about 15 states with prescription monitoring programs. The program was very successful in encouraging other states. Of note, in the past, another source of support for prescription monitoring programs at the state level was the National All Schedules Prescription Electronic Reporting Act of 2005. However, this source has not continued.

Evaluations of the programs suggest that they are effective, particularly in the overall reduction of prescription of pain management medications and also in increasing physician awareness of this issue. More research is needed. Some of the prescription monitoring programs are not proactive and only provide information when asked. There is a range of medications that the different prescription monitoring programs monitor in different states (many focus on Schedule IV and/ or Schedule III medications) and most of the misused medications are in Schedule III. The National Alliance For Model State Drug Laws provides updates on these programs. Another source of information on prescription monitoring programs is on the Alliance of State Pain Initiatives website (http://trc. wisc.edu/), which has an informative position paper.

Another state level intervention is creating policies that define what an addiction is. There is great variability amongst states, and this topic is important to distinguish between physical dependence that can occur even with appropriate prescribing and taking of these medications. Patients with substance use disorders are at high risk of chronic traumainduced pain and do need acute pain management. These definitions can sometimes lead to reduced quality of care for this population, which is of course weighed against the issue of misuse of prescription pain relief medications.

\section{US Food and Drug Administration}

In response to the current epidemic of opioid-related deaths, the FDA intends to require opioid manufacturers to provide training for both clinicians and patients on the appropriate prescribing and use of opioid analgesics. However, in July 2010, an advisory panel (comprising the Anesthetic and Life Support Drugs Advisory Committee and Drug Safety and
Risk Management Advisory Committee) rejected the FDA risk evaluation and mitigation strategy (REMS). The majority of members noted that the proposed REMS simply did not go far enough. The REMS, which was proposed to apply solely to long-acting opioid analgesics, should be extended to all opioids, irrespective of the setting in which they are prescribed. In addition to making pain management training mandatory for any clinicians seeking a Drug Enforcement Administration number, the advisory panel indicated that patients should bear a greater burden of responsibility for their own treatment. Committee recommendations included registration of patients who receive long-term opioid therapy and signing treatment agreements. While the final FDA decision on its REMS is not available, the response to opioid abuse and unintentional death will likely have an impact on patients and providers alike.

\section{Conclusion}

Opioid analgesic abuse in the context of chronic pain treatment can be a complex issue. This issue is gaining an increasing amount of attention on an international scale. While researchers are scrambling to identify empirically validated treatment options across the pharmacological, psychological, and social domains; governmental legislators and state medical boards are attempting to implement programs to increase education for providers and reduce diversion. Despite this recent attention, a number of serious challenges remain in the treatment of chronic pain in the context of opioid misuse. There are many treatments that have not been empirically validated, there are challenges to using methadone and buprenorphine to treat comorbid pain and addiction, and there are limited educational opportunities for physicians and psychologists who wish to treat patients with chronic pain and opioid misuse. As the field continues to develop strong integrated psychological-pharmacological treatment paradigms, it is hoped that we can reduce the instances of misuse and prevent many cases from progressing to the level of comorbid addiction.

\section{Disclosure}

The authors report no conflicts of interest in this work.

\section{References}

1. Gilson AM, Ryan KM, Joranson DE, Dahl JL. A reassessment of trends in the medical use and abuse of opioid analgesics and implications for diversion control: 1997-2002. J Pain Symptom Manage. 2004;28: 176-188.

2. Compton WM, Volkow ND. Major increases in opioid analgesic abuse in the United States: concerns and strategies. Drug Alcohol Depend. 2006;81:103-107. 
3. Drug Abuse Warning Network.. In: Health and Human Services (DHHS), editor. National Estimates of Drug-related Emergency Department Visits. Washington, DC: department of Health and Human Services; 2004.

4. Elliott AM, Smith BH, Penny KI, Smith WC, Chambers WA. The epidemiology of chronic pain in the community. Lancet. 1999;354: 1248-1252.

5. Schappert SM. National Ambulatory Medical Care Survey: 1989summary. Vital Health Stat 13. 1992;110:1-80.

6. Stewart WF, Ricci JA, Chee E, Morganstein D, Lipton R. Lost productive time and cost due to common pain conditions in the US workforce. JAMA. 2003;290:2443-2454.

7. Turk DC. Clinical effectiveness and cost-effectiveness of treatments for patients with chronic pain. Clin J Pain. 2002;18:355-365.

8. Joranson DE, Ryan KM, Gilson AM, Dahl JL. Trends in medical use and abuse of opioid analgesics. JAMA. 2000;283:1710-1714.

9. Ives TJ, Chelminski PR, Hammett-Stabler CA, et al. Predictors of opioid misuse in patients with chronic pain: a prospective cohort study. $B M C$ Health Serv Res. 2006;6:46.

10. Reiger DA, Farmer ME, Rae DS, et al. Comorbidity of mental disorders with alcohol and other drug abuse. JAMA. 1990;264:2511-2518.

11. Fishbain DA, Cole B, Lewis J, Rosomoff HL, Rosomoff RS. What percentage of chronic nonmalignant pain patients exposed to chronic opioid analgesic therapy develop abuse/addiction and/or aberrant drug-related behaviors? A structured evidence-based review. Pain Med. 2008;9:444-459.

12. Rosenblum A, Joseph H, Fong C, Kipnis S, Cleland C, Portenoy RK. Prevalence and characteristics of chronic pain among chemically dependent patients in methadone maintenance and residential treatment facilities. JAMA. 2003;289:2370-2378.

13. Larson MJ, Paasche-Orlow M, Cheng DM. Persistent pain is associated with substance use after detoxification: a prospective cohort analysis Addiction. 2007;102:752-760.

14. Okie S. A flood of opioids, a rising tide of deaths. N Engl J Med. 2010; 363:1981-1985.

15. Melzack R. From the gate to the neuromatrix. Pain. 1999;6: S121-S126.

16. Turk DC, Okifuji A. Psychological factors in chronic pain: evolution and revolution. J Consult Clin Psychol. 2002;70:678-690.

17. Eisenberger NI, Lieberman MD, Williams KD. Does rejection hurt? An fMRI study of social exclusion. Science. 2003;302:290-292.

18. Wachholtz AB, Pearce MJ, Koenig HG. Exploring the relationship between spirituality, coping, and pain. J Behav Med. 2007;30: 311-318.

19. Bair M, Robinson R, Katon W, Kroenke K. Depression and pain comorbidity: a literature review. Arch Intern Med. 2003;163: 2433-2445.

20. Zelman DC, Howland EW, Nichols SN, Cleeland CS. The effects of induced mood on laboratory pain. Pain. 1991;46:105-111.

21. Edwards RR, Haythornthwaite JA, Sullivan MJ, Fillingim RB. Catastrophizing as a mediator of sex differences in pain: differential effects for daily pain versus laboratory-induced pain. Pain. 2004;111: 335-341.

22. Keefe FJ, Lefebvre JC, Maixner W, Jr. ANS, Caldwell DS. Self-efficacy for arthritis pain: relationship to perception of thermal laboratory pain stimuli. Arthritis Care Res. 1997;10:177-184.

23. Adams EH, Breiner S, Cicero TJ, et al. A comparison of the abuse liability of tramadol, NSAIDs, and hydrocodone in patients with chronic pain. J Pain Symptom Manage. 2006;31:465-476.

24. Martell BA, O'Connor PG, Kerns RD, et al. Systematic review: opioid treatment for chronic back pain: prevalence, efficacy, and association with addiction. Ann Intern Med. 2007;146:116-127.

25. Hojsted J, Sjogren P. Addiction to opioids in chronic pain patients: a literature review. Eur J Pain. 2007;11:490-518.

26. Miotto K, Compton P, Ling W, Conolly M. Diagnosing addictive disease in chronic pain patients. Psychosomatics. 1996;37: 223-235.
27. Compton P, Darakjian J, Miotto K. Screening for addiction in patients with chronic pain and "problematic" substance use: evaluation of a pilot assessment tool. J Pain Symptom Manage. 1998;16:355-363.

28. Portenoy RK, Hagen NA. Breakthrough pain: definition, prevalence and characteristics. Pain. 1990;41:273-281.

29. Brodner RA, Taub A. Chronic pain exacerbated by long-term narcotic use in patients with nonmalignant disease: clinical syndrome and treatment. Mt Sinai J Med. 1978;45:233-237.

30. Mathew NT, Kurman R, Perez F. Drug induced refractory headache clinical features and management. Headache. 1990;30:634-638.

31. Portenoy RK. Chronic opioid therapy in nonmalignant pain. J Pain Symptom Manage. 1990;5:S46-S62.

32. Dunbar SA, Katz NP. Chronic opioid therapy for nonmalignant pain in patients with a history of substance abuse: report of 20 cases. J Pain Symptom Manage. 1996;11:163-171.

33. Perdue Pharma. Drug Safety and Risk Management Advisory Committee. 2009. Available from: http://www.fda.gov/downloads/ AdvisoryCommittees/CommitteesMeetingMaterials/Drugs/DrugSafetyandRiskManagementAdvisoryCommittee/UCM164897.pdf. Accessed July 12, 2011.

34. Lee S, Park Y, Han E, et al. Thebaine in hair as a marker for chronic use of illegal opium poppy substances. Forensic Sci Int. 2011;204: 115-118.

35. Hahm ET, Kim Y, Lee JJ, Cho YW. GABAergic synaptic response and its opioidergic modulation in periaqueductal gray neurons of rats with neuropathic pain. BMC Neurosci. 2011;12:41.

36. Corbett AD, Henderson G, McKnight AT, Paterson SJ. 75 years of opioid research: the exciting but vain quest for the Holy Grail. Br J Pharmacol. 2006;147(Suppl 1):S153-S162.

37. Ossipov MH, Lai J, King T, et al. Antinociceptive and nociceptive actions of opioids. J Neurobiol. 2004;61:126-148.

38. Mollereau C, Parmentier M, Mailleux P, et al. ORL1, a novel member of the opioid receptor family. Cloning, functional expression and localization. FEBS Lett. 1994;341:33-38.

39. Chevillard L. Mechanisms of respiratory insufficiency induced by methadone overdose in rats. Addict Biol. 2009;15:62-80.

40. Arvidsson U, Riedl M, Chakrabarti S, et al. Distribution and targeting of a mu-opioid receptor (MOR1) in brain and spinal cord. J Neurosci. 1995;15(5 Pt 1):3328-3341.

41. Holzer P. Opioid receptors in the gastrointestinal tract. Regul Pept. 2009;155:11-17.

42. Furlan AD, Sandoval JA, Mailis-Gagnon A, Tunks E. Opioids for chronic noncancer pain: a meta-analysis of effectiveness and side effects. CMAJ. 2006;174:1589-1594.

43. Glass PS, Jhaveri RM, Smith LR. Comparison of potency and duration of action of nalmefene and naloxone. Anesth Analg. 1994;78: 536-541.

44. Moore RA, McQuay HJ. Prevalence of opioid adverse events in chronic non-malignant pain: systematic review of randomised trials of oral opioids. Arthritis Res Ther. 2005;7:R1046-R1051.

45. Eisenberg E, McNicol ED, Carr DB. Efficacy of mu-opioid agonists in the treatment of evoked neuropathic pain: systematic review of randomized controlled trials. Eur J Pain. 2006;10:667-676.

46. Daniell HW. Opioid endocrinopathy in women consuming prescribed sustained-action opioids for control of nonmalignant pain. J Pain. 2008;9:28-36

47. Angst MS, Clark JD. Opioid-induced hyperalgesia: a qualitative systematic review. Anesthesiology. 2006;104:570-587.

48. Vadivelu N, Mitra S, Hines RL. Peripheral opioid receptor agonists for analgesia: a comprehensive review. J Opioid Manag. 2011;7:55-68.

49. Sam WJ, MacKey SC, Lotsch J, Drover DR. Morphine and its metabolites after patient-controlled analgesia: considerations for respiratory depression. J Clin Anesth. 2011;23:102-106.

50. Hervera A, Negrete R, Leanez S, Martin-Campos JM, Pol O. Peripheral effects of morphine and expression of mu-opioid receptors in the dorsal root ganglia during neuropathic pain: nitric oxide signaling. Mol Pain. $2011 ; 7: 25$ 
51. Kirchheiner J, Schmidt H, Tzvetkov M, et al. Pharmacokinetics of codeine and its metabolite morphine in ultra-rapid metabolizers due to CYP2D6 duplication. Pharmacogenomics J. 2007;7:257-265.

52. Foster D, Upton R, Christrup L, Popper L. Pharmacokinetics and pharmacodynamics of intranasal versus intravenous fentanyl in patients with pain after oral surgery. Ann Pharmacother. 2008;42:1380-1387.

53. Jumbelic MI. Deaths with transdermal fentanyl patches. Am J Forensic Med Pathol. 2010;31:18-21.

54. Dhalla IA, Mamdani MM, Sivilotti ML, Kopp A, Qureshi O, Juurlink DN. Prescribing of opioid analgesics and related mortality before and after the introduction of long-acting oxycodone. CMAJ. 2009;181:891-896.

55. Ward J, Bell J, Mattick RP. Methadone maintenance treatment and other opioid replacement therapies. Methadone Maintenance Therapy for Opioid Dependence: A Guide to Appropriate Use. In Ward J, Mattick RP, Hall W, editors. Sydney, Australia: Harwood Academic Publishers; 1996.

56. Brown R, Kraus C, Fleming M, Reddy S. Methadone: applied pharmacology and use as adjunctive treatment in chronic pain. Postgrad Med J. 2004;80:654-659.

57. Blinderman CD, Sekine R, Zhang B, Nillson M, Shaiova L. Methadone as an analgesic for patients with chronic pain in methadone maintenance treatment programs (MMTPs). J Opioid Manag. 2009;5:107-114.

58. Rhodin A, Gronbladh L, Nilsson LH, Gordh T. Methadone treatment of chronic non-malignant pain and opioid dependence - a long-term follow-up. Eur J Pain. 2006;10:271-278.

59. Krantz MJ. Heterogeneous impact of methadone on the QTc interval: what are the practical implications? J Addict Dis. 2008;27:5-9.

60. Krantz MJ, Martin J, Stimmel B, Mehta D, Haigney MC. QTc interval screening in methadone treatment. Ann Intern Med. 2009;150:387-395.

61. Martell BA, Arnsten JH, Ray B, Gourevitch MN. The impact of methadone induction on cardiac conduction in opiate users. Ann Intern Med. 2003;139:154-155.

62. Cruciani RA, Sekine R, Homel P, et al. Measurement of QTc in patients receiving chronic methadone therapy. J Pain Symptom Manage. 2005; 29:385-391.

63. Bruce RD. Pharmacokinetic drug interactions between opioid agonist therapy and antiretroviral medications: implications and management for clinical practice. J Acquir Immune Defic Syndr. 2006;41:563-572.

64. Perret G, Deglon JJ, Kreek MJ, Ho A, La HR. Lethal methadone intoxications in Geneva, Switzerland, from 1994 to 1998. Addiction. 2000;95:1647-1653.

65. Mattick RP, Breen C, Kimber J, Davoli M. Methadone maintenance therapy versus no opioid replacement therapy for opioid dependence. Cochrane Database Syst Rev. 2003;2:CD002209.

66. Cooper JR. Including narcotic addiction treatment in an office-based practice. JAMA. 1995;273:1619-1620.

67. Novick DM, Joseph H, Salsitz EA, et al. Outcomes of treatment of socially rehabilitated methadone maintenance patients in physicians' offices (medical maintenance): follow-up at three and a half to nine and a fourth years. J Gen Intern Med. 1994;9:127-130.

68. Novick DM, Pascarelli EF, Joseph H, et al. Methadone maintenance patients in general medical practice. A preliminary report. JAMA. 1988;259:3299-3302.

69. Graham NA, Merlo LJ, Goldberger BA, Gold MS. Methadone- and heroin-related deaths in Florida. Am J Drug Alcohol Abuse. 2008;34: 347-353.

70. Fudala PJ, Yu E, Macfadden W, Boardman C, Chiang CN. Effects of buprenorphine and naloxone in morphine-stabilized opioid addicts. Drug Alcohol Depend. 1998;50:1-8.

71. Kuhlman JJ Jr, Levine B, Johnson RE, Fudala PJ, Cone EJ. Relationship of plasma buprenorphine and norbuprenorphine to withdrawal symptoms during dose induction, maintenance and withdrawal from sublingual buprenorphine. Addiction. 1998;93:549-559.

72. Amass L, Kamien JB, Mikulich SK. Thrice-weekly supervised dosing with the combination buprenorphine-naloxone tablet is preferred to daily supervised dosing by opioid-dependent humans. Drug Alcohol Depend. 2001;61:173-181.
73. Petry NM, Bickel WK, Badger GJ. Examining the limits of the buprenorphine interdosing interval: daily, every-third-day and everyfifth-day dosing regimens. Addiction. 2001;96:823-834.

74. Walsh SL, Preston KL, Stitzer ML, Cone EJ, Bigelow GE. Clinical pharmacology of buprenorphine: ceiling effects at high doses. Clin Pharmacol Ther. 1994;55:569-580.

75. Walsh SL, Preston KL, Bigelow GE, Stitzer ML. Acute administration of buprenorphine in humans: partial agonist and blockade effects. J Pharmacol Exp Ther. 1995;274:361-372.

76. Lange WR, Fudala PJ, Dax EM, Johnson RE. Safety and side-effects of buprenorphine in the clinical management of heroin addiction. Drug Alcohol Depend. 1990;26:19-28.

77. Huestis MA, Umbricht A, Preston KL. Safety of buprenorphine: no clinically relevant cardio-respiratory depression at high IV doses. Problems of Drug Dependence. In: Harris LS, editor. Washington, DC: US Government Printing Office; 1999.

78. Pergolizzi J, Boger RH, Budd K, et al. Opioids and the management of chronic severe pain in the elderly: consensus statement of an International Expert Panel with focus on the six clinically most often used World Health Organization Step III opioids (buprenorphine, fentanyl, hydromorphone, methadone, morphine, oxycodone). Pain Pract. 2008;8:287-313.

79. Ballantyne JC, LaForge KS. Opioid dependence and addiction during opioid treatment of chronic pain. Pain. 2007;129:235-255.

80. Johnson RE, Fudala PJ, Payne R. Buprenorphine: considerations for pain management. J Pain Symptom Manage. 2005;29:297-326.

81. Ling W, Charuvastra C, Collins JF, et al. Buprenorphine maintenance treatment of opiate dependence: a multicenter, randomized clinical trial. Addiction. 1998;93:475-486.

82. Fiellin DA, Pantalon MV, Pakes JP, O'Connor PG, Chawarski M, Schottenfeld RS. Treatment of heroin dependence with buprenorphine in primary care. Am J Drug Alcohol Abuse. 2002;28:231-241.

83. McDiarmid T, Mackler L, Schneider DM. Clinical inquiries. What is the addiction risk associated with tramadol? J Fam Pract. 2005;54: $72-73$.

84. Kroenke K, Krebs EE, Bair MJ. Pharmacotherapy of chronic pain: a synthesis of recommendations from systematic reviews. Gen Hosp Psychiatry. 2009;31:206-219.

85. Gonzalez G, Oliveto A, Kosten TR. Combating opiate dependence: a comparison among the available pharmacological options. Expert Opin Pharmacother. 2004;5:713-725.

86. Silverman SM. Opioid induced hyperalgesia: clinical implications for the pain practitioner. Pain Physician. 2009;12:679-684.

87. Kasimcan O, Kaptan H. Efficacy of gabapentin for radiculopathy caused by lumbar spinal stenosis and lumbar disk hernia. Neurol Med Chir (Tokyo). 2010;50:1070-1073.

88. Ucak A, Onan B, Sen H, Selcuk I, Turan A, Yilmaz AT. The effects of gabapentin on acute and chronic postoperative pain after coronary artery bypass graft surgery. J Cardiothorac Vasc Anesth. January 11, 2011. [Epub ahead of print].

89. Folkesson A, Honore PH, Andersen LM, Kristensen P, Bjerrum OJ. Low dose of donepezil improves gabapentin analgesia in the rat spared nerve injury model of neuropathic pain: single and multiple dosing studies. $J$ Neural Transm. 2010;117:1377-1385.

90. Crofford LJ, Rowbotham MC, Mease PJ, et al. Pregabalin for the treatment of fibromyalgia syndrome: results of a randomized, doubleblind, placebo-controlled trial. Arthritis Rheum. 2005;52:1264-1273.

91. Arnold LM, Russell IJ, Diri EW, et al. A 14-week, randomized, doubleblinded, placebo-controlled monotherapy trial of pregabalin in patients with fibromyalgia. J Pain. 2008;9:792-805.

92. Crofford LJ, Mease PJ, Simpson SL, et al. Fibromyalgia relapse evaluation and efficacy for durability of meaningful relief (FREEDOM): a 6-month, double-blind, placebo-controlled trial with pregabalin. Pain. 2008;136:419-431.

93. Mease PJ, Russell IJ, Arnold LM, et al. A randomized, double-blind, placebo-controlled, phase III trial of pregabalin in the treatment of patients with fibromyalgia. $J$ Rheumatol. 2008;35:502-514. 
94. Recla JM. New and emerging therapeutic agents for the treatment of fibromyalgia: an update. J Pain Res. 2010;3:89-103.

95. PDR Network, LLC. Available from: http://www.pdr.net/drugpages/ productlabeling. aspx ?mpcode $=62950900$. Accessed July 13, 2011 .

96. Filipetto FA, Zipp CP, Coren JS. Potential for pregabalin abuse or diversion after past drug-seeking behavior. $J$ Am Osteopath Assoc. 2010;110:605-607.

97. Arnold LM, Lu Y, Crofford LJ, et al. A double-blind, multicenter trial comparing duloxetine with placebo in the treatment of fibromyalgia patients with or without major depressive disorder. Arthritis Rheum. 2004;50:2974-2984.

98. Arnold LM, Rosen A, Pritchett YL, et al. A randomized, double-blind, placebo-controlled trial of duloxetine in the treatment of women with fibromyalgia with or without major depressive disorder. Pain. 2005; 119:5-15.

99. Chappell AS, Bradley LA, Wiltse C, Detke MJ, D'Souza DN, Spaeth M. A six-month double-blind, placebo-controlled, randomized clinical trial of duloxetine for the treatment of fibromyalgia. Int J Gen Med. 2009;1:91-102.

100. Mease PJ, Russell IJ, Kajdasz DK, et al. Long-term safety, tolerability, and efficacy of duloxetine in the treatment of fibromyalgia. Semin Arthritis Rheum. 2010;39:454-464.

101. Russell IJ, Mease PJ, Smith TR, et al. Efficacy and safety of duloxetine for treatment of fibromyalgia in patients with or without major depressive disorder: results from a 6-month, randomized, double-blind, placebo-controlled, fixed-dose trial. Pain. 2008;136:432-444.

102. Arnold LM, Clauw DJ, Wohlreich MM, et al. Efficacy of duloxetine in patients with fibromyalgia: pooled analysis of 4 placebo-controlled clinical trials. Prim Care Companion J Clin Psychiatry. 2009; 11:237-244.

103. Greden JF. Duloxetine and milnacipran In: Schatzberg AF, Nemeroff CB, editors. Essentials of Clinical Psychopharmacology. 2nd ed. Arlington, VA: American Psychiatric Publishing Inc; 2006.

104. Shuto S, Ono S, Hase Y, et al. Synthesis and biological activity of conformationally restricted analogs of milnacipran: (1S,2R)-1-phenyl2-[(S)-1-aminopropyl]-N,N-diethylcyclopropanecarboxamide, an efficient noncompetitive $\mathrm{N}$-methyl-D-aspartic acid receptor antagonist. J Med Chem. 1996;39:4844-4852.

105. Nebel MB, Gracely RH. Neuroimaging of fibromyalgia. Rheum Dis Clin North Am. 2009;35:313-327.

106. Nagaoka S, Ohno M, Sekiguchi A. An open-label clinical trial of milnacipran in fibromyalgia syndrome with co-morbid depressive symptoms. Int Clin Psychiatry Clin Pract. 2004;8:47-51.

107. Branco JC, Zachrisson O, Perrot S, Mainguy Y. A European multicenter randomized double-blind placebo-controlled monotherapy clinical trial of milnacipran in treatment of fibromyalgia. $J$ Rheumatol. 2010;37:851-859.

108. Vitton O, Gendreau M, Gendreau J, Kranzler J, Rao SG. A double-blind placebo-controlled trial of milnacipran in the treatment of fibromyalgia. Hum Psychopharmacol. 2004;19 Suppl 1:S27-S35.

109. Dharmshaktu P, Tayal V, Kalra BS. Efficacy of antidepressants as analgesics: a review. J Clin Pharmacol. March 17, 2011. [Epub ahead of print].

110. McQuay HJ, Tramér M, Nye BA, Carroll D, Wiffen PJ, Moore RA. A systematic review of antidepressants in neuropathic pain. Pain. 1996;68:217-227.

111. Melief EJ, Miyatake M, Bruchas MR, Chavkin C. Ligand-directed c-Jun N-terminal kinase activation disrupts opioid receptor signaling. Proc Natl Acad Sci U S A. 2010;107:11608-11613.

112. Chavkin C. The therapeutic potential of kappa-opioids for treatment of pain and addiction. Neuropsychopharmacology. 2011;36:369-370.

113. Li XY, Ko HG, Chen T, et al. Alleviating neuropathic pain hypersensitivity by inhibiting PKMzeta in the anterior cingulate cortex. Science. 2010;330:1400-1404.

114. Prochaska JO, DiClemente CC. Toward a comprehensive model of change. In: Miller W, Heather N, editors. Treating Addictive Behavior: Processes of Change. New York, NY: Plenum Press; 1986.
115. Savage $\mathrm{S}$. Assessment for addiction in pain-treatment settings. Clin $J$ Pain. 2002;18:S28-S38.

116. Eccleston C. Role of psychology in pain management. Br J Anaesth. 2001;87:144-152.

117. Rounsaville BJ, Carroll KM. Individual psychotherapy for drug abusers. In: Lowinsohn J, Ruiz P, Miller R, editors. Comprehensive Textbook of Substance Abuse. New York, NY: Williams and Wilkins; 1997.

118. Cheatle MD, Gallagher RM. Chronic pain and comorbid mood and substance use disorders: a biopsychosocial treatment approach. Curr Psychiatry Rep. 2006;8:371-376.

119. Fordyce WE. Behavioral Methods for Chronic Pain and Illness. Saint Louis, MO: Mosby; 1976.

120. Molton IRG, Stoelb C, Jensen BL. Current psychological approaches to the management of chronic pain. Curr Opin Anasthesiol. 2007; 20:485-489.

121. Stitzer M, Petry N. Contingency management for treatment of substance abuse. Annu Rev Clin Psychol. 2006;2:411-434.

122. Mayet S, Farrell M, Ferri MMF, Amato L, Davoli M. Psychosocial treatment for opiate abuse and dependence. Cochrane Database Syst Rev. 2005;1:CD004330.

123. Seybold K. Physiological mechanisms involved in religiosity/spirituality and health. J Behav Med. 2007;30:303-309.

124. National Institutes of Health. NIH Consensus Development Conference on Acupuncture. JAMA. 1998;280:1518-1524.

125. Ezzo J, Berman B, Hadhazy VA, Jadad AR, Lao L, Singh BB. Is acupuncture effective for the treatment of chronic pain? A systematic review. Pain. 2000;86:217-225.

126. Arnold RM, Avants SK, Margolin A, Marcotte D. Patient attitudes concerning the inclusion of spirituality into addiction treatment. J Subst Abuse Treat. 2002;23:319-326.

127. Barry DT, Beitel M, Cutter CJ, Joshi D, Falcioni J, Schottenfeld R. Conventional and nonconventional pain treatment utilization among opioid dependent individuals with pain seeking methadone maintenance treatment: a needs assessment study. $J$ Addict Med. 2009;18: 379-385.

128. Carson J, Keefe F, Lynch T, et al. Loving-kindness meditation for chronic low back pain: results from a pilot trial. J Holist Nurs. 2005; 23:287-304.

129. Morone NE, Greco CM. Mind-body interventions for chronic pain in older adults: a structured review. Pain Med. 2007;8:359-375.

130. Wachholtz A, Pargament K. Migraines and meditation: does spirituality matter? J Behav Med. 2008;31:351-366.

131. Daley DC, Marlatt GA. Relapse prevention: cognitive and behavioral interventions. In: Lowinson JH, Ruiz P, Millman RB, Langrod JG, editors. Substance Abuse: A Comprehensive Textbook. 2nd ed. Baltimore, MD: Williams and Wilkins; 1992.

132. Vallejo Z, Amaro H. Adaptation of mindfulness-based stress reduction program for addiction relapse prevention. The Humanistic Psychologist. 2009;37:192-206.

133. Kabat-Zinn J, Lipworth L, Burney R, Sellers W. Four-year follow-up of a meditation based program for the self-regulation of chronic pain: treatment outcomes and compliance. Clin J Pain. 1986;2:159-173.

134. Rosenzweig S, Greeson JM, Reibel DK, Green JS, Jasser SA, Beasley D. Mindfulness-based stress reduction for chronic pain conditions: variation in treatment outcomes and role of home meditation practice. J Psychosom Res. 2010;68:29-36.

135. Zgierska A, Rabago D, Chawla N, Kushner K, Koehler R, Marlatt A. Mindfulness meditation for substance use disorders: a systematic review. Subst Abuse. 2009;30:266-294.

136. Ziedonis DM, Berman J, Lehn MD, Coameco S. Support groups and twelve-step programs in the treatment of the chronic pain patient. Pain and Chemical Dependency. In: Smith HS, Passik SD, editors. New York, NY: Oxford University Press; 2008.

137. Martelli M, Liljedahl E, Nicholson K, Zasler N. A brief introductory guide to chronic pain resources on the Internet. NeuroRehabilitation. 2000;14:105-121. 
138. American Chronic Pain Association. Ten Steps. 2011. Available from: http://www.theacpa.org/21/TenSteps.aspx. Accessed May 6, 2011.

139. Davis W, Johnson B. Prescription opioid use, misuse, and diversion among street drug users in New York City. Drug Alcohol Depend. 2008;92:267-76.
140. Ezyk B. Prescription drug monitoring programs. 2008. Available from: http://www.codrugfreeworkplace.org/files/documents/White $\% 20$ paper\%20-PDMP\%207-08\%20with\%20logos.pdf. Accessed March 2, 2011.

\section{Publish your work in this journal}

Substance Abuse and Rehabilitation is an international, peer-reviewed, open access journal publishing original research, case reports, editorials, reviews and commentaries on all areas of addiction and substance abuse and options for treatment and rehabilitation. The manuscript management system is completely online and includes a very quick and fair peer-review system. Visit http://www.dovepress.com/testimonials. php to read real quotes from published authors. 